\section{Lethal respiratory failure due to a surfactant protein C gene mutation}

\author{
SRĐAN BANAC • SANDRO DESSARDO • KRISTINA LAH-TOMULIĆ \\ NEVEN FRLETA • NADA SINDIČIĆ-DESSARDO • GIORDANO ŠAINA \\ KSENIJA LUČIN
}

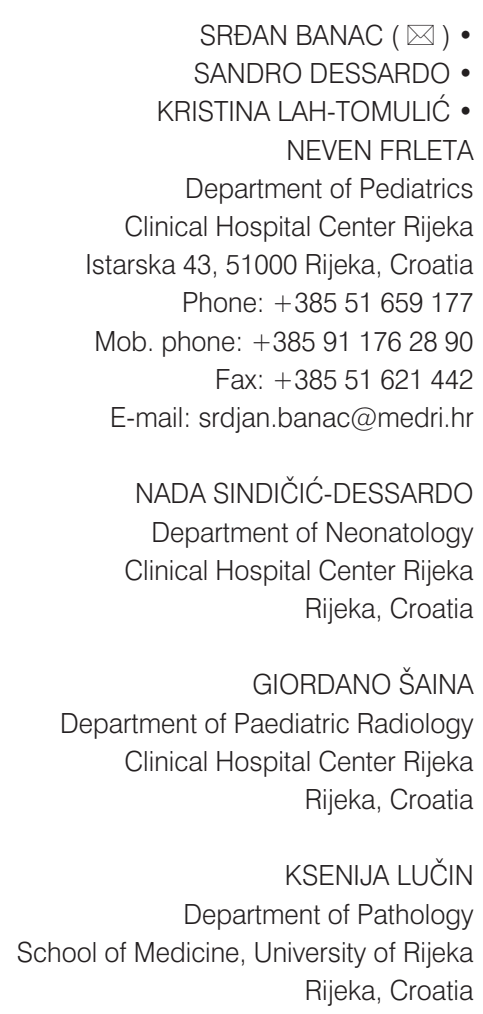

$\operatorname{SREAN~BANAC~}(\square) \cdot$ SANDRO DESSARDO • KRISTINA LAH-TOMULIĆ • NEVEN FRLETA

Department of Pediatrics Clinical Hospital Center Rijeka Istarska 43, 51000 Rijeka, Croatia Phone: +38551659177 Mob. phone: +38591176 2890

Fax: +385 51621442

E-mail: srdjan.banac@medri.hr

NADA SINDIČIĆ-DESSARDO

Department of Neonatology

Clinical Hospital Center Rijeka

Rijeka, Croatia

GIORDANO ŠAINA

Department of Paediatric Radiology

Clinical Hospital Center Rijeka

Rijeka, Croatia

KSENIJA LUČIN

Department of Pathology

School of Medicine, University of Rijeka

Rijeka, Croatia

\begin{abstract}
A case of a full-term male infant with recurrent episodes of „obstructive bronchitis” and „bilateral pneumonias”, refractory to conventional asthma therapy, is reported. When referred to the paediatric clinic at the age of 15 months, his clinical presentation was of acute respiratory distress syndrome with severe hypoxemia, which was easily corrected by the inhalation of oxygen. A series of further investigations, including lung biopsy, suggested the diagnosis of childhood interstitial lung disease (ILD). Due to progressive respiratory failure, the boy died after 3 months of mechanical ventilator support, at the age of 19 months. Subsequently performed genetic studies revealed that he was heterozygous for the I73T mutation of the surfactant protein $C$ precursor protein. Thus, suspicion of childhood ILD due to genetic mutations that influence surfactant metabolism should be raised in children who present with unexplained respiratory distress or chronic respiratory symptoms. Less invasive testing, such as surfactant protein genetics, may be diagnostic in such cases.
\end{abstract}

Key words: child, interstitial lung disease, respiratory distress, surfactant deficiency, surfactant protein C

\section{Introduction}

Consideration of childhood interstitial lung disease (ILD) due to genetic mutations that influence surfactant metabolism should be raised in children who present with acute or chronic respiratory symptoms in the absence of known causes of respiratory distress or lung disease. (1)

\section{Case report}

A 15-month old boy was transferred from a paediatric department of a general hospital to the paediatric clinic because of acute exacerbation of his chronic respiratory symptoms. The boy was tachypneic and cyanotic on admission and needed oxygen administration by mask. Without oxygen supplementation his blood saturation immediately dropped to $40 \%$ and vice versa - severe hypoxemia was promptly corrected by the inhalation of oxygen. The boy was immediately admitted to the paediatric intensive care unit. At initial assessment digital clubbing, as a sign of chronic hypoxemia, was noticed. Blood gases analysis showed a normal blood carbon dioxide partial pressure $\left(\mathrm{pCO}_{2}\right)$ value. The ratio of blood oxygen partial pressure $\left(\mathrm{pO}_{2}\right)$ to fraction of inhaled oxygen $\left(\mathrm{FiO}_{2}\right)$ was 135 . Echocardiography displayed a normal image of the heart and great vessels. Chest radiography showed bilateral lung infiltrates suggesting acute respiratory distress 
syndrome (figure 1). Chest auscultation revealed normal breath sounds in both lungs. There were no adventitious sounds, including wheezing or crackles. The boy had severe failure to thrive with a body weight of $7700 \mathrm{~g}$. Birth history (birth weight $3300 \mathrm{~g}$; Apgar score 10/10), as well as his growth and development until the age of 7 months, were unremarkable. Then, recurrent episodes of "obstructive bronchitis" and "bilateral pneumonias", usually triggered by viral airway infections, started to characterize his clinical presentations. During the following 8 months he was hospitalized four times at various paediatric departments and underwent many investigations including chest radiography, sweat tests and skin prick tests. Several consultants concluded that the boy was an immunocompetent, non-atopic subject who did not suffer from cystic fibrosis. He was treated with bronchodilators, inhaled corticosteroids and antileukotrienes, with no effect.

When referred to the paediatric clinic, a series of further investigations were performed. Bronchoscopy revealed normal visual findings. However, high-resolution computed tomography (HRCT) of the thorax showed impressive widespread changes (figure 2). Since the boy's condition deteriorated, open lung biopsy was performed. Microscopic examination showed an organising phase of diffuse alveolar damage which appeared to be superimposed on hypoplastic lung.

Inspite of theadministration of corticosteroids, azathioprine, hydroxychloroquine and intravenous immunoglobulins, the boy's condition continued to be critical. The progressive respiratory failure led to mechanical ventilation dependency, characterized by a continuous increase in mean airway pressure and $\mathrm{FiO}_{2}$ to maintain acceptable blood gas levels. Three doses of exogenous surfactant were administered with only short-term benefit. A trial of high frequency oscillatory ventilation was performed but the boy was unresponsive to unconventional ventilation. He died after 3 months of mechanical ventilator support, at the age of 19 months.

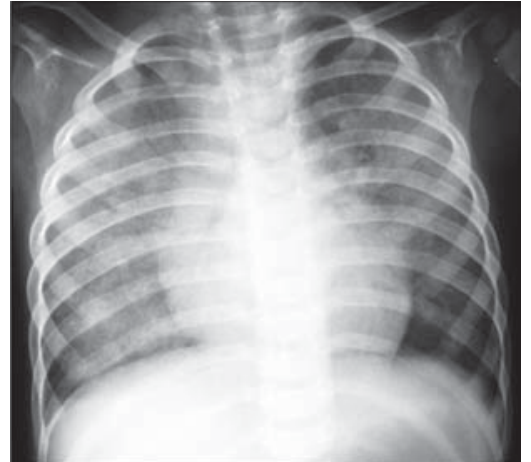

Figure 1. Chest radiograph on admission to the clinic, at age 15 months, showed bilateral fluffy alveolar infiltrates.

Subsequently performed genetic studies revealed that the boy was heterozygous for the 173T gene mutation of the surfactant protein C (SP-C). Gene analysis for ABCA3 mutation was negative. His healthy unrelated parents did not wish to have their DNA analysed. They have two healthy daughters.

\section{Discussion}

Children younger than 15 months of age who have recurrent respiratory symptoms, with a fluctuating level of wheeze and dyspnea, may have developed symptoms following acute viral bronchiolitis, may have one of the asthma phenotypes, or may have some other disorder including childhood ILD syndrome. (2) ILD is a rare diagnosis in children and its clinical presentation can be very nonspecific. Severe hypoxemia with normal $\mathrm{pCO}_{2}$, which was easily corrected with administration of oxygen, presence of finger clubbing and spectacular weight loss were clues to the diagnosis of ILD in the reported case. Diagnosis is usually confirmed by HRCT, but most patients will need to proceed to surgical lung biopsy for definitive diagnosis. (3)

The boy in our case showed no particular benefit from exogenous surfactant administration. The turn-over period of exogenous surfactant determines only temporary and partial improvement of lung compliance and gas exchange since there is no restoration of endo-

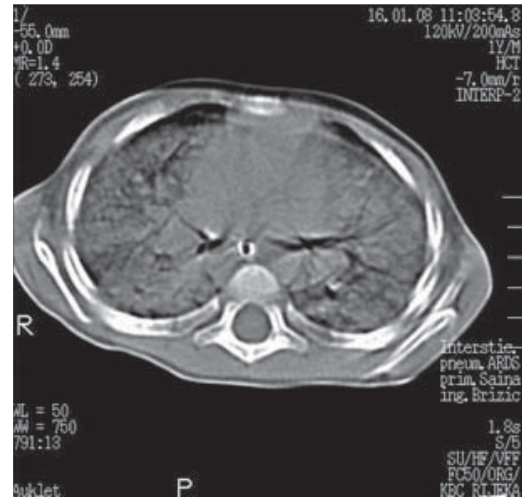

Figure 2. High-resolution computed tomography of the chest showed diffuse bilateral air space consolidation with air bronchograms.

genous surfactant activity due to the genetic error. The progressive character of the disease, as well as the transient response to surfactant replacement therapy, was also the standpoint for the diagnosis of ILD due to surfactant deficiency.

Childhood ILD comprises a much wider spectrum of conditions than the adult version. Genetic mutations in genes that influence surfactant metabolism, including SP-B, SP-C and ABCA3, can result in several histologic forms of ILD. Thus, less invasive testing, such as surfactant protein genetics, may be diagnostic in a certain proportion of cases. (4) The I73T mutation is the most frequently identified SP-C gene mutation, and has accounted for approximately $30 \%$ of at least 35 mutations described in patients with lung disease due to SP-C gene mutations. (5) There is tremendous variability in the severity of the lung disease associated with this mutation. Some children die in early infancy, whereas other subjects with the mutation do not develop pulmonary symptoms until the fifth or sixth decade of life. (6) It is not clear why the lung disease is more severe in some individuals. In a small proportion of such patients it was found that they were also carriers for an ABCA3 mutation. (7) Given that lung disease due to SP-C mutation can be familial and transmitted in an autosomal dominant pattern, the possibility of testing the boy's parents 
for this mutation was discussed. Because of the variable severity of lung disease associated with this mutation, it is quite possible that one of them has the mutation, and is currently without symptoms, but at risk for developing ILD in the future. However, their reluctance to perform the analysis was somewhat understandable as there is currently no specific treatment for the lung disease due to SP-C gene mutations. (8) Furthermore, history revealed that no other family members or relatives died from unexplained lung disease or had a life-long history of chronic respiratory problems or atypical asthma. Suppo- sing that neither parent carries the I73T mutation, then it could be a de novo mutational event causing sporadic lung disease in the boy. In such a scenario, the chances of parents having another affected child would be very small but unfortunately not zero due to possible germ-line mosaicism.

\section{ACKNOWLEDGMENTS}

We would like to thank professor Lawrence Nogee (Johns Hopkins University School of Medicine, Baltimore) and professor Andrew Bush (Royal Brompton Hospital, London) for their suggestions, genetic studies and kind help in executing this clinical case.

\section{REFERENCES}

1. Redding GJ, Deterding RR, Fan LL. Interstitial lung disease. In: Taussig LM, Landau LI, editors. Pediatric respiratory medicine, 2nd ed. Philadelphia: Mosby; 2008. p. 661-9.

2. Springer C, Godfrey S. The approach to the child with apparent pediatric chronic lung disease. In: Kerem E, Canny GJ, Branski D, Levison H, editors. Advances in pediatric pulmonology. Pediatr Adolesc Med. Basel: Karger; 1997. vol 7. p. 125-37.

3. Clement A, Allen J, Corrin B, Dinwiddie V, Ducou le Pointe H, Eber E, et al. Task force on chronic interstitial lung disaese in immunocompetent children. Eur Respir J 2004;24:686-697.

4. Bush A, Nicholson AG. Paediatric interstitial lung disease. Eur Respir Mon 2009:46:319-354.

5. Cameron HS, Somaschini M, Carrera P, Hamvas A, Whitsett JA, Wert SE, et al. A common mutation in the surfactant protein C gene associated with lung disease. J Pediatr 2005;146:370-375

6. Bush A. Paediatric interstitial lung disease: not just kid's stuff. Eur Respir J 2004;24;521-523.

7. Bullard JE, Nogee LM. Heterozygosity for ABCA3 mutations modifies the severity of lung disease associated with a surfactant protein $\mathrm{C}$ gene mutation. Pediatr Res 2007;62:176-179.

8. Clement A, Eber E. Interstitial lung diseases in infants and children. Eur Respir J 2008;31:658-666 